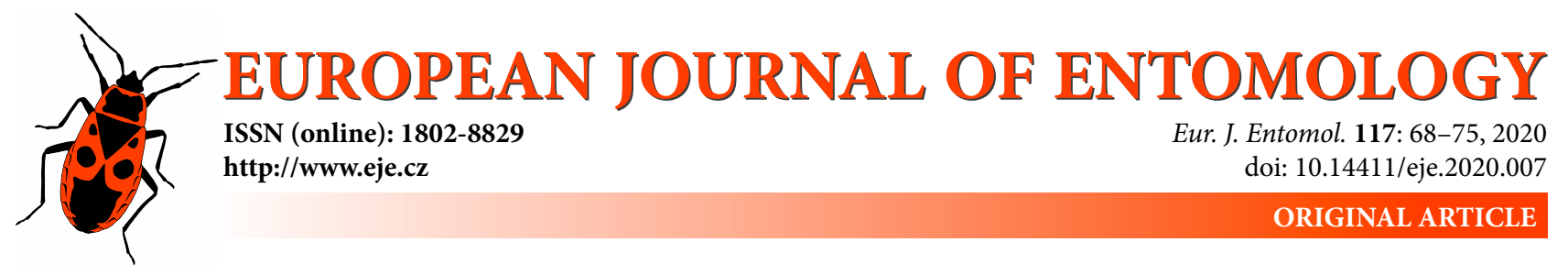

\title{
Seasonal fluctuations and development of degree-day models for Chilo partellus (Lepidoptera: Crambidae) in maize fields in the Mediterranean region
}

\author{
Tange Denis AChIRI, Ekrem AtAKan and Serkan Pehlivan \\ Department of Plant Protection, Agricultural Faculty, University of Çukurova, Adana, Turkey; e-mails: achiritange@gmail.com, \\ eatakan@mail.cu.edu.tr, spehlivan@cu.edu.tr
}

Key words. Lepidoptera, Crambidae, Chilo partellus, seasonal fluctuation, degree-day model, Akaike, biofix, Boltzman, logistic regression, phenology, maize, Mediterranean

\begin{abstract}
Chilo partellus Swinhoe 1885 (Lepidoptera: Crambidae) is a serious pest of maize in many parts of the world. It was reported for the first time in 2014 in the Mediterranean part of Turkey. Degree-Day (DD) models were developed to predict seasonal dynamics in maize fields using 3-parameter 'Boltzman' and a 4-parameter Logistic regressions. Larval/plant counts were monitored in pesticide-free maize fields in Adana, Turkey from 2017 to 2019 . Depending on the year, the first record of $C$. partellus was between 03-14 May, corresponding to 9-12 DD accumulated from 01 May. There were two main peaks; one in each of the maize growing seasons. The models accurately predicted the phenology of $C$. partellus with an Adj. $R^{2}$ greater than 0.80 . The 'Boltzman' regression had lower AICc, $\triangle \mathrm{AICc}$ and $W \mathrm{v}$ values than the logistic regression. Based on the 'Boltzman' model, $50 \%$ of the accumulated larvae/plant count for the first and second generations (peaks) occurred at 80DD and 375DD, 81DD and 413DD, and 54DD and 289DD in 2017, 2018 and 2019, respectively. For the logistic regression model, 50\% of the accumulated larvae/ plant counts occurred for the first and second generation at 90DD and 362DD, 62DD, and 45DD and 250DD in 2017, 2018, and 2019 , respectively. Both these models could play a crucial role in the integrated pest management (IPM) of C. partellus in maize fields in Mediterranean regions.
\end{abstract}

\section{INTRODUCTION}

The effects of abiotic factors (e.g. temperature and humidity) on cold-blooded animals, such as insects, are widely reported (Rahman \& Khalequzzaman, 2004, and references therein). Temperature, far more than relative humidity, plays an important role in determining the abundance and distribution of insects (Rahman \& Khalequzzaman, 2004; Machekano et al., 2019 and references therein). Entomologists and ecologists have exploited the temperature-insect relationship to predict and forecast certain biological events such as egg laying, egg hatch, migration, population peaks, flight patterns and appearance after overwintering (Chapman et al., 2002; Damos \& SavopoulouSoultani, 2010; Akotsen-Mensah et al., 2011; Karuppaiah \& Sujayanad, 2012; Pehlevan \& Kovanc1, 2017). This relationship is conveniently described by the concept of Degree-days (DD) and there are a number of rate functions or models based on parameters, numbers and simple assumptions about the effects of temperature between the lower and upper limits (Pruess, 1983; Lactin et al., 1995). In other words, insect development and activity patterns over time can be predicted based on heat units accumulated over a period above a certain temperature threshold (Potter, 1981).

Degree-day models are considered as reliable tools for predicting the population dynamics of many lepidopteran pests (Del Tio et al., 2001). These models assist in pest management decision-making (Damos \& SavopoulouSoultani, 2010; Akotsen-Mensah et al., 2011; Pehlevan \& Kovanci, 2017) by predicting many biological events. For instance, Demir \& Kovanc1 (2015) constructed linear and nonlinear models for predicting emergence time of the codling moth Cydia pomonella (L., 1758) in the field. In addition, phenological models can be used to predict the flight activity of Adoxophyes orana (Fischer von Röslerstamm, 1834) (Lepidoptera: Tortricidae) in apple orchards (Kocourek \& Stara, 2005) and peach orchards (Damos \& Savopoulous-Soultani, 2010). Detecting and predicting the activities of pests may help farmers properly plan pesticide applications, release natural enemies, etc, to coincide with different biological events such as emergence, hatching time and population peaks of pests.

Chilo partellus is an important pest of maize, damaging both its reproductive and vegetative parts and causing 
about $80-100 \%$ loss of crop if not controlled (Overholt et al., 2000; Arabjafali \& Jalali, 2007). In addition, it is considered to be an important pest because of its ability to spread into other geographical regions, given the constantly changing micro and macro climatic conditions (Yonow et al., 2017). It is reported that $C$. partellus has the potential to displace indigenous stem borers in many of the areas it invades (Ofomata et al., 2000).

In 2014, C. partellus was recorded in the Mediterranean regions of Turkey for the first time (Sertkaya et al., 2014). Sesamia nonagrioides Lefebvre (Lepidoptera: Noctuidae) and Ostrinia nubilalis (Hübner) (Lepidoptera: Crambidae) are the indigenous maize stem borers in Turkey, causing very severe damage to maize especially in the second maize growing season (here after referred as second crop) between July-September (Okyar \& Kornoşor, 1997). The use of synthetic insecticides still plays a major role in the management of C. partellus (Kfir et al., 2002; Kumar, 2002; Rauf et al., 2017), with a few farmers adopting 'push-pull' technology in East Africa (Van den Berg, 2006). The negative unintended effects of synthetic insecticides, especially calendar-based applications, on humans and the environment have necessitated the need for more benign pest control practices (Achiri et al., 2016). Consequently, integrated pest management (IPM) will be beneficial for maize farmers in Turkey and most probably in the Mediterranean area generally. There are many universal IPM models, which include the DD concept; however these universal models do not always fit some local situations given the changing micro and global climatic conditions (IPCC, 2014), which highlights the need for locally developed models. Mudavanhu et al. (2011) and Crespo-Perez et al. (2011) further posit that locally developed IPM models based on in situ field data are essential for purposes of early awareness in pest management. Having established that understanding the spatio-environmental responses of insect populations to temperature under varying local-specific climatic condition is an important part of IPM, this study was designed to (1) monitor the population of C. partellus and (2) develop Degree-Day models for forecasting $C$. partellus phenology in maize fields in Turkey, using in situ counts of field population recorded in the 2017, 2018 and 2019 maize growing seasons.

\section{MATERIALS AND METHODS}

\section{Study location}

The study was conducted in the Agriculture and Research Application Field of Cukurova University, Adana, Turkey $\left(39^{\circ} 01^{\prime} 50.5^{\prime \prime} \mathrm{N}, 35^{\circ} 21^{\prime} 06.7^{\prime \prime} \mathrm{E}\right)$ from $2017-2019$. This site is used for agricultural research by the aforementioned university, thus at any given time, there are multiple crops growing in the area. Every year, maize is predominantly grown in two seasons in Turkey; first crop (March-June) and a second crop (July-October). A maize (Pioneer Hybrid 1/2013) field of 1 acre was established in each maize growing season. Inter-row and intra-row spacing was $45 \mathrm{~cm}$ and $20 \mathrm{~cm}$, respectively. In the month of July both fields were adjacent to one another separated by a $\sim 10 \mathrm{~m}$ wide gap. No chemicals were applied to the maize plants for pest control during the entire period of study.

\section{Insect sampling}

Given that $C$. partellus has an aggregated spatial distribution, the field was divided into four quadrants (NW, NE, SW, SE), and 15 plants were sampled from each quadrant. Sampling began on 01 April in every year. Sampling was done between 08.00-10.00 am. The maize plants were cut at ground level and then taken to the Entomology laboratory, Department of Plant Protection, Cukurova University, Adana, Turkey. The maize stalks were dissected and the numbers of $C$. partellus larvae ( $3^{\text {rd }}-6^{\text {th }}$ instars) were counted as well as those of other stem borers. Records were also taken from the leaves, cobs and tassel. Sampling was done once a week throughout the entire study in 2017, 2018 and 2019. Sampling ended when no larvae were recorded on two consecutive sampling dates. Other agronomic practices such as fertilization and irrigation were done ad libitum.

\section{Temperature data and degree-days (DD)}

Daily minimum $\left(\mathrm{T}_{\min }\right)$ and maximum $\left(\mathrm{T}_{\max }\right)$ air temperature data were obtained from the meteorological station at the experimental site. The DD accumulated after the $1^{\text {st }}$ of May (when first larvae were recorded) was estimated using the summation equation (1):

$$
\sum_{1}^{n} D D=\int_{1}^{n}\left[\frac{T_{\max }+T_{\min }}{2}-T_{b}\right] d T
$$

where DD is the daily degree-days, $\mathrm{T}_{\max }$ is the maximum daily temperature and $T_{\min }$ is the minimum daily temperature, and $T_{b}$ is the minimum temperature threshold. The minimum temperature threshold of $10^{\circ} \mathrm{C}$ for $C$. partellus was adopted from Dhillon \& Hasan (2018). The $1^{\text {st }}$ of May was used as the start point because it is in this month that the first larvae were recorded on maize.

\section{Statistical analysis}

A simple linear regression was used to evaluate the effect of temperature and relative humidity on the number of larvae. Chisquare test was used to determine whether the number of larvae recorded in 2017 was significantly different from that recorded in 2018 . For all analysis, $\alpha$ was $5 \%$ when hypothesis testing. Analysis was done using SPSS (ver. 23).

\section{Models used to predict the $\mathrm{DD}_{50}$ of the first and second peak populations of Chilo partellus}

Two models based on the data collected in 2019 were developed to predict the seasonal peaks of $C$. partellus in maize fields. The relationship between the cumulative DD (independent variable) and the weekly count of $C$. partellus (dependent variable) was used in these models based on 1 May as the starting point. These nonlinear regression models were used because they are sshaped types of cumulative distribution functions, which are suitable for numerical work with parameters. First, the 3-parameter 'Boltzman' regression equation (2) was used on the data.

$$
f(x)=\frac{\alpha}{1+e^{((-x-c) / b)}}
$$

where, $x$ is the accumulated degree days, and $\alpha, b$ and $c$ are constants; $a$ and $b$ is the upper and lower asymptote of the curve, while $\mathrm{c}$ is the gradient of the curve and is the time $\left(\mathrm{DD}_{50}\right)$ of $50 \%$ moth emergence (Damos \& Savopoulou-Soultani, 2010).

Secondly, the 4-parameter 'Logistic' regression (3) was fitted to the data.

$$
g(x)=d+\frac{\alpha}{1+(x / c)^{b}}
$$

where $g$ is the cumulative percentage of $C$. partellus catches, $x$ is the accumulated degree-days, and $\alpha, b, c$ and $d$ are constant numerical parameters. These parameters regulate the shape of the 
logistic regression function. In addition, parameter $\mathrm{c}$ indicates the time $\left(\mathrm{DD}_{50}\right)$ of $50 \%$ moth emergence (Damos \& SavopoulouSoultani, 2010; Pehlevan \& Kovanc1, 2017).

The parameters of these models were estimated based on iterative ordinary least squares (OLS), with the Levenberg-Marquard algorithm (IBM SPSS ver. 23), in which the cumulative C. partellus numbers were the independent variable using the pooled data for 2017 and 2018.

A Pearson correlation analysis was used to assess the relationship between the observed and the model's predicted occurrence of population generations.

\section{Statistical evaluation of models' predictive performance}

For each model, the Adjusted coefficient of determination (Adj. $R^{2}$ ), and an Akaike Information Criteria (AIC) were calculated using the data for 2019 (equation 3 and 4, respectively)

$\operatorname{Adj} R^{2}=1-\frac{\left[\frac{R S S}{n}-(\theta+1)\right]}{\frac{S S}{n}-1}$

$A I C=n \ln \left(\frac{R S S}{n}\right)+2 \theta$

where, RSS is the residual sum of squares, $\mathrm{n}$ is the number of samples, $\theta$ is the number of parameters, SS is the total sum of squares. Adj. $R^{2}$ and AIC are usually used to statistically compare the performance and accuracy of models (Akaike, 1974; Burham \& Anderson, 2002; Damos \& Savopouou-Soultani, 2010; Akotson-Mensah et al., 2011; Pehlevan \& Kovanc1, 2017). Due to the relatively small sample sizes and a high number of parameters in the models, the AIC was corrected (AICc) for sample size using equation 5 .

$A I C c=n \ln \left(\frac{R S S}{n}\right)+2 \theta+\frac{2 \theta(\theta+1)}{(n-\theta-1)}$

where, RSS is the residual sum of squares, $n$ is the number of samples and $\theta$ is the number of parameters. In order to select a better model, Delta $(\Delta)$ scores of AIC and Akaike weights $\left(W_{i}\right)$ were calculated using formula 7 and 8 , respectively. The weight is backed up by the $\Delta$ and AICc in determining a better model.

$\Delta_{i}=A I C c_{i}-A I C c_{\text {smallest }}$

$W i=\frac{e^{-0.5 \Delta_{i}}}{\sum_{r=1}^{N} e^{\left(-0.5 \Delta_{r}\right)}}$

where, $\mathrm{N}$ is number of regression ( $\mathrm{r}$ ) models.

\section{RESULTS}

\section{Population dynamics of larvae of Chilo partellus}

The interplay of temperature and relative humidity on the population dynamics of $C$. partellus is shown in Fig. 1 for 2017, 2018 and 2019. The temperature during the study period ranged from $20.25-30.88^{\circ} \mathrm{C}, 19.51-29.87^{\circ} \mathrm{C}$ and $19.63-29.75^{\circ} \mathrm{C}$ in 2017,2018 and 2019 , respectively. The degree-days (DD) followed the same pattern as the weekly mean temperature. The weekly mean temperatures in 2017 and 2018 were not significantly different $\left(\chi^{2}=0.168, \mathrm{df}=1\right.$, $p=0.682)$. The relative humidity (RH\%) during the study period ranged from 55.0-67.15 RH\%, 24.51-67.38 RH\% and 48.69-71.5 RH\% in 2017, 2018 and 2019, respectively. In 2017 , the first and second peaks were recorded on 11 May and 20 July, respectively. The first and second peaks occurred on 21 May and 02 August in 2018. In 2018, the major peak was recorded in the first crop between 5-11 June. Two small peaks were recorded in the mixed and second crop between 22 July-07 August. Since both small peaks occurred over a short time interval it is likely they were of the same generation. In 2019, the first and second peaks were recorded on 31 May and 02 August. The total number of larvae collected in the same period in 2017 was significantly higher $\left(\chi^{2}=33.989, \mathrm{df}=1, p=0.001\right)$ than in 2018. In general, regression analysis revealed that the relationships between temperature and humidity and the mean number of larvae of $C$. partellus were not significant for the first and second crop of maize in this study (Table 1).

\section{Percentage (\%) cumulative numbers of larvae of Chilo partellus per maize plant}

The percentage (\%) cumulative numbers of larvae of $C$. partellus recorded in 2017, 2018, pooled (2017 \& 2018) and 2019 against cumulated degree-days (DD) is given in Fig. 2. The first peak occurred on 11 May and 21 May in 2017 and 2018, respectively, corresponding to the accumulation of 12 and 24 degree-days, respectively. Both the 2017 and 2018 first peaks ended on the same day, 25 June, corresponding to the accumulation of 98 degree-days. The first peak of 2019 followed a very similar pattern as in 2017 and 2018, however ending on 28 June, corresponding to the accumulation of 135 degree-days. The second peak in 2017 and 2018 started in the same week, ( $~ 5$ July), corresponding to the accumulation of 116 degree-days. The second peak ended between 05 and 12 October in 2017 and 2018 , corresponding to an accumulation of 372 and 387 degree-days, respectively. On the other hand, the second-

Table 1. Regression relationships between the numbers of larvae of Chilo partellus and temperature and relative humidity in the first and second crops of maize in 2017, 2018 and 2019.

\begin{tabular}{ccccccccc}
\hline \multirow{2}{*}{ Parameter } & \multirow{2}{*}{ Maize season } & \multicolumn{3}{c}{ Temperature } & & \multicolumn{2}{c}{ Humidity } \\
\cline { 3 - 4 } \cline { 7 - 8 } & & Regression equation & R2 & P-value & & Regression equation & R2 & P-value \\
\hline \multirow{2}{*}{2017} & First crop & $y=310.277-11.06 x$ & 0.435 & 0.330 & & $y=150.958-1.470 x$ & 0.123 & 0.793 \\
& Second crop & $y=115.45 x-3023.33$ & 0.589 & 0.107 & & $y=889.77-8.67 x$ & 0.180 & 0.805 \\
\multirow{2}{*}{2018} & First crop & $y=257.702-7.802 x$ & 0.665 & 0.013 & & $y=24.588-0.046 x$ & 0.121 & 0.693 \\
& Second crop & $y=0.412 x-9.584$ & 0.444 & 0.111 & & $y=6.720-0.082 x$ & 0.619 & 0.018 \\
& First crop & $y=0.016 x-0.272$ & 0.417 & 0.138 & & $y=0.439-0.005 x$ & 0.219 & 0.452 \\
& Second crop & $y=0.186 x-4.599$ & 0.519 & 0.102 & & $y=0.054 x-2.859$ & 0.307 & 0.359 \\
\hline
\end{tabular}



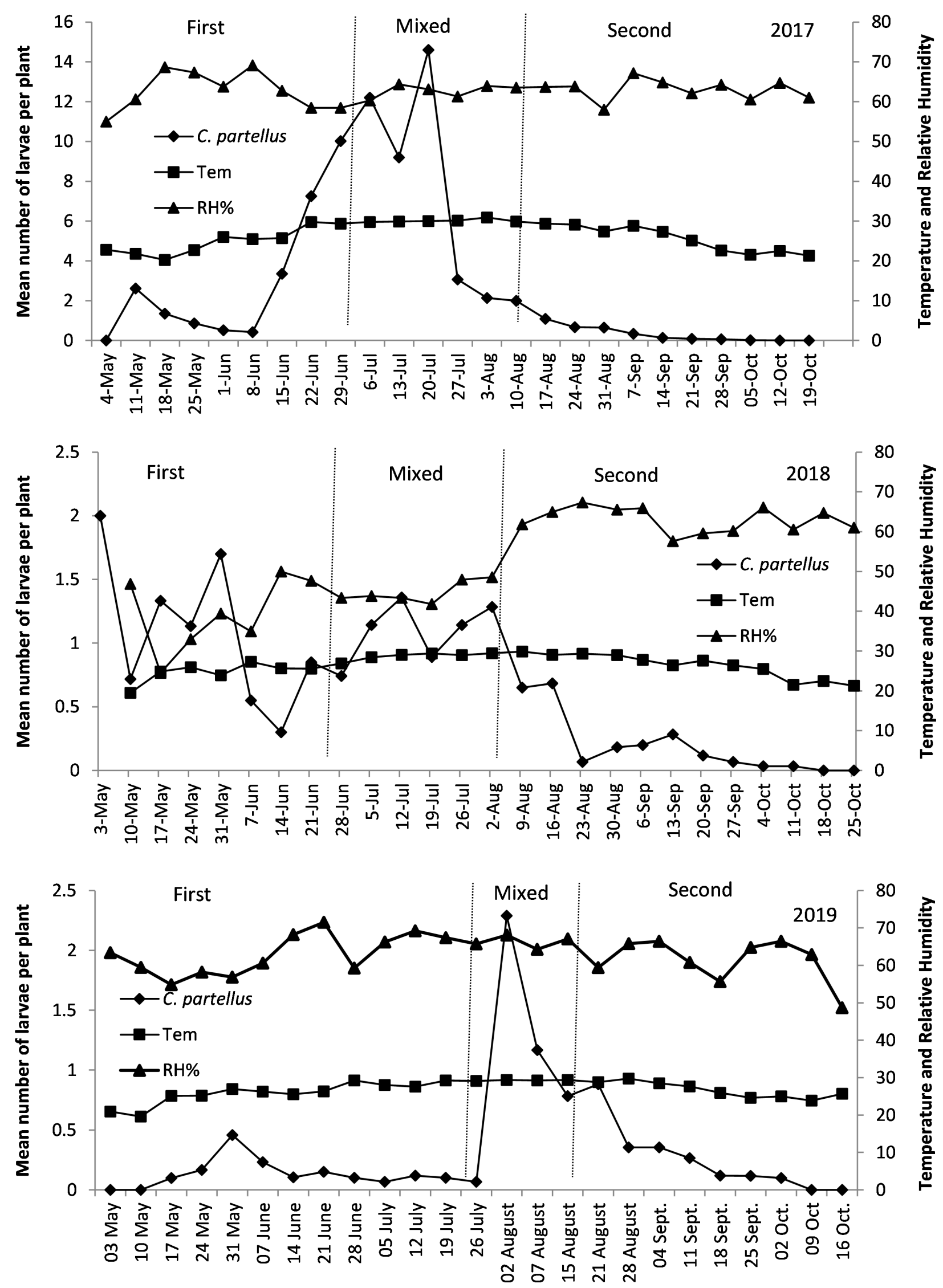

Fig. 1. Population dynamics of larvae of Chilo partellus in the two maize growing seasons in 2017, 2018 and 2019. First - first maize growing season; Second - second maize growing season, and Mixed - are the months within which both first and second crops were present in the field. 


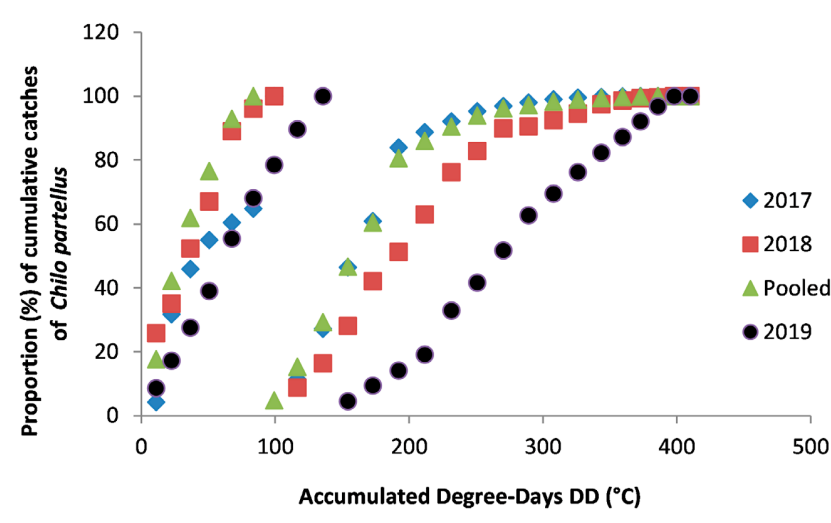

Fig. 2. Percentage cumulative numbers of larvae of Chilo partellus and cumulated degree-days for the first and second crop in 2017, 2018 and 2019 and pooled data for 2018 and 2019.

peak in 2019 started rather later, 13 July, and ended on 19 October, corresponding to an accumulation of 153 and 401 degree-days, respectively.

\section{Parameters of the forecasting models}

The parameters of the 3-parameter 'Boltzman' and 4-parameter logistic regression models used to estimate the times of the peak periods of Chilo partellus in maize fields are given in Table 2. The parameter c of the 'Boltzman' and logistic regression models is $50 \%$ of the cumulative numbers of Chilo partellus recorded in each season. The 'Boltzman' and logistic regression models predicted 60 DD and 65 DD for peak 1, respectively. For the first peak, the $R^{2}$ values were 0.769 and 0.886 for 'Boltzman' and logistic regression models, respectively. For the second peak, the predictions were 264 DD and 278 DD for 'Boltzman' and logistic regresion models, respectively. The $R^{2}$ value for the second peaks were 0.754 and 0.743 for 'Boltzman' and logistic regressions, respectively. The estimated parameters of the 3-parameter 'Boltzman' and 4-parameter logistic regression models are summarized in Table 2.

Parameters were estimated based on pooled data in order to obtain an average performance of the models. $a$ and $b$ are the lower and upper asymptotes of the regression function curve. $\mathrm{c}$ is the cummulative DD at which $50 \%$ of the larvae are recorded in each generation. $d$ is a contant adjusting the shape of the curve.

\section{Statistical evaluation of regression models}

The observed and predicted regression statistics for the 3-parameter 'Boltzman' and 4-parameter logistic regres-
Table 2. Parameter estimates and coefficient of determinations of two non-linear models used to describe the phenology of Chilo partellus: 3-parameter 'Boltzman' and 4-parameter logistic regression.

\begin{tabular}{|c|c|c|c|c|}
\hline \multirow{2}{*}{ Peaks } & \multicolumn{4}{|c|}{ Parameter estimates } \\
\hline & \multicolumn{2}{|c|}{ ‘Boltzman' function } & \multicolumn{2}{|c|}{ Logistic regression function } \\
\hline \multirow{5}{*}{ Peak 1} & a & 1.133 & a & -93.343 \\
\hline & $b$ & 0.4 & $\mathrm{~b}$ & -0.269 \\
\hline & $c$ & 61 & c & 65 \\
\hline & - & & d & 93.494 \\
\hline & $R^{2}$ & 0.769 & $R^{2}$ & 0.886 \\
\hline \multirow{5}{*}{ Peak 2} & a & 2.135 & a & 6.992 \\
\hline & $b$ & 0.01 & b & -2.061 \\
\hline & c & 264 & c & 278 \\
\hline & - & & d & -5.554 \\
\hline & $R^{2}$ & 0.754 & $R^{2}$ & 0.743 \\
\hline
\end{tabular}

sion models based on the data for 2019 are summarized in table 3. The $R^{2}$ values for all models and all the peaks were greater than 0.9. The corrected Akaike Information Criterion (AICc) for 'Boltzman' and logistic regression models were 30.122 and 34.396 , respectively, for the first peak and 17.167 and 56.341, respectively, for the second peak. For both peaks, the 'Boltzman' regression model had a lower Akaike delta score $(\triangle \mathrm{AICc})$ than the logistic regression model and consequently a lower Akaike weight ( $W i)$.

\section{Regression functions used to predict seasonal peaks}

The mean numbers of C. partellus in the first and second peaks in 2019 were fitted using the 3-parameter 'Boltzman' and and the 4-parameter logistic regression functions as shown in Fig. 3. Fig. 3a shows the recorded first peak and predicted first peak using the 'Boltzman' regression. A strong Pearson product-moment coefficient (r) was recorded $\left(\mathrm{r}^{2}=0.990, \mathrm{n}=9, p=0.0001\right)$ between the recorded and the predicted peaks. The second recorded peak and second predicted using the 'Boltzman' regression model is presented in Fig. 3b. A strong positive correlation was recorded $\left(\mathrm{r}^{2}\right.$ $=0.973, \mathrm{n}=16, p=0.0001$ ) between the recorded and the predicted peaks. The recorded first peak and predicted first peak using the logistic regression function is shown in Fig. $3 \mathrm{c}$. A strong positive correlation was recorded $\left(\mathrm{r}^{2}=0.976\right.$, $\mathrm{n}=9, p=0.0001)$. A strong positive correlation $\left(\mathrm{r}^{2}=0.973\right.$, $\mathrm{n}=16, p=0.0001)$ was also recorded between the recorded second peak and predicted second peak using the logistic regression function (Fig. 3d).

The parameters of the 'Boltzman' and the logistic regression equations based on the pooled data were used to fit

Table 3. Regression statistics for predicted versus observed percentages, and statistical classification criteria of two non-linear regression models, the 3-parameter 'Boltzman' and 4-parameter logistic regression used to describe the phenology of Chilo partellus.

\begin{tabular}{|c|c|c|c|c|c|c|c|c|c|c|}
\hline \multirow{2}{*}{ Peak } & \multicolumn{5}{|c|}{ Regression characteristics } & \multicolumn{5}{|c|}{ Statistical information criterion } \\
\hline & Model & $\mathrm{n}$ & Regression equation & $R^{2}$ & $\operatorname{Adj} R^{2}$ & $\mathrm{~F}$ & $\mathrm{AIC}$ & $\mathrm{AICc}$ & $\triangle \mathrm{AICc}$ & $W i$ \\
\hline \multirow{2}{*}{1} & Boltzman & 9 & $y=10.67+0.726 x$ & 0.980 & 0.977 & 336.181 & 30.122 & 34.922 & 0 & $<0.001$ \\
\hline & Logistic & 9 & $y=19.293+0.674 x$ & 0.963 & 0.957 & 179.952 & 34.396 & 44.396 & 9.474 & 1 \\
\hline \multirow{2}{*}{2} & Boltzman & 16 & $y=0.349 x-48.44$ & 0.997 & 0.987 & 5089.15 & 17.167 & 19.167 & 0 & $<0.001$ \\
\hline & Logistic & 16 & $y=0.320 x-25.65$ & 0.964 & 0.961 & 371.039 & 56.341 & 59.981 & 40.814 & 1 \\
\hline
\end{tabular}

$\mathrm{n}$ - number of samples, Adj $R^{2}$ - Adjusted $R$ square, AIC - Akaike's Information Criterion, AICc - corrected Akaike's Information Criterion, $\triangle \mathrm{AIC}-\mathrm{AIC}$ delta scores (relative difference between it and the best model), $W_{1}-$ Akaike weights (probability of being the best model). The values in bold indicate better model performance with regard to the statistical criteria used. 

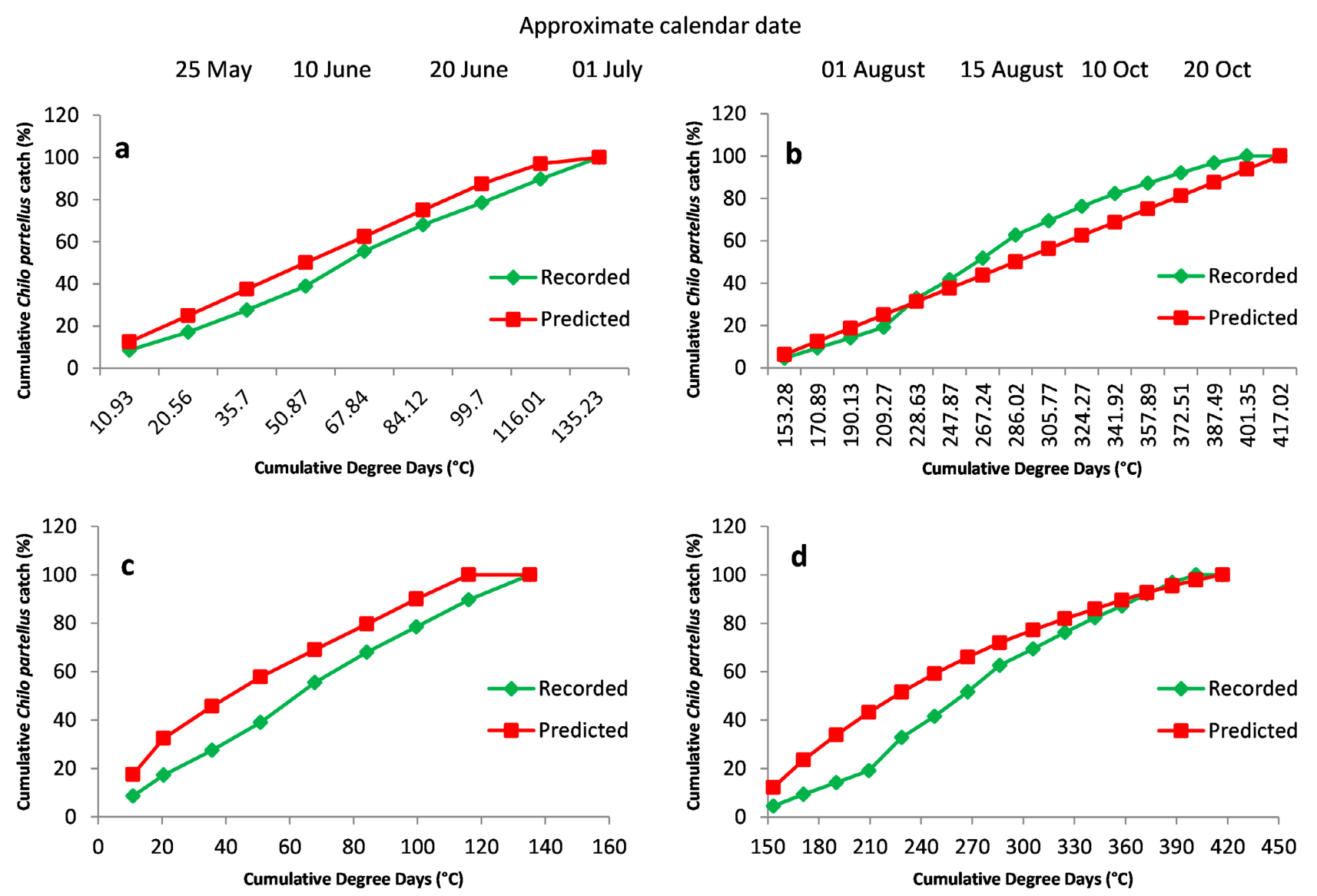

Fig. 3. Recorded and predicted cumulative numbers of Chilo partellus relative to cumulative degree-days (DD) based on data collected in maize fields in Adana, Turkey, in 2019 and using the 3-parameter 'Boltzman' and 4-parameter logistic regressions. a - first peak predicted by 'Boltzman' regression, $b$ - second peak predicted by 'Boltzman' regression, $c$ - first peak predicted by logistic regression, $d$ - second peak predicted by logistic regression.

a curve for all the data collected in this study (Table 4). There were good fits between recorded and predicted data for the first and second peaks for both models. The $R^{2}$ value were greater than 0.80 for all peaks except the second peak in 2017, irrespective of the model used.

\section{DISCUSSION}

Chilo partellus is reported to be spreading in Mediterranean regions (Yonow et al., 2017). The first report in the Mediterranean area of Turkey was in 2014 (Sertkaya et al., 2014). Larvae/plant counts have been successfully used for surveillance and predictions of insect phenology (Manyangarirwa et al., 2009, Mosiane et al., 2003; Marchioro \&

Table 4. The 3-parameter 'Boltzman' and 4-parameter logistic regression functions used to predict the phenology of Chilo partellus in 2017, 2018 and 2019, and the recorded and predicted $D_{50}$ of the peaks.

\begin{tabular}{|c|c|c|c|c|c|c|c|c|c|}
\hline Peak & Year & $\mathrm{n}$ & Model & Regression equation & $R^{2}$ & Adj. $R^{2}$ & AIC & $\mathrm{DD}_{50}$ Recorded & $\mathrm{DD}_{50}$ Predicted \\
\hline \multirow{6}{*}{1} & \multirow{2}{*}{2017} & 7 & Boltzman & $y=0.532 x+2.050$ & 0.912 & 0.894 & 33.376 & 90.13 & 80.50 \\
\hline & & 7 & Logistic & $y=0.532 x+2.050$ & 0.912 & 0.894 & 33.376 & 90.13 & 90.13 \\
\hline & \multirow{2}{*}{2018} & 7 & Boltzman & $y=0.551 x+15.078$ & 0.967 & 0.960 & 26.656 & 63.38 & 81.06 \\
\hline & & 7 & Logistic & $y=0.551 x+15.084$ & 0.967 & 0.960 & 26.652 & 63.37 & 62.51 \\
\hline & \multirow{2}{*}{2019} & 9 & Boltzman & $y=10.67+0.726 x$ & 0.980 & 0.977 & 30.122 & 64.01 & 54.19 \\
\hline & & 9 & Logistic & $y=19.293+0.674 x$ & 0.963 & 0.957 & 34.396 & 64.01 & 45.56 \\
\hline \multirow{6}{*}{2} & \multirow{2}{*}{2017} & 16 & Boltzman & $y=0.179 x+7.191$ & 0.707 & 0.686 & 90.781 & 239.16 & 375.37 \\
\hline & & 16 & Logistic & $y=0.179 x+7.193$ & 0.707 & 0.686 & 90.78 & 239.15 & 362.76 \\
\hline & \multirow{2}{*}{2018} & 17 & Boltzman & $y=0.208 x-16.593$ & 0.878 & 0.870 & 84.436 & 320.16 & 413.03 \\
\hline & & 17 & Logistic & $y=0.208 x-16.587$ & 0.878 & 0.870 & 84.441 & 320.13 & 337.18 \\
\hline & \multirow{2}{*}{2019} & 16 & Boltzman & $y=0.349 x-48.44$ & 0.997 & 0.987 & 17.167 & 269.635 & 289.635 \\
\hline & & 16 & Logistic & $y=0.320 x-25.65$ & 0.964 & 0.961 & 56.341 & 269.635 & 252.167 \\
\hline
\end{tabular}

$\mathrm{n}$ - number of samples, Adj $R^{2}$ - Adjusted $R$ square, AIC - Akaike's Information Criterion, $\mathrm{DD}_{50}$ - cumulative degree-days at which $50 \%$ of the larvae of Chilo partellus were present each peak. Regression equation, $R^{2}, \operatorname{Adj} R^{2}, \mathrm{AIC}_{\text {and }} \mathrm{DD}_{50}$ were based on recorded data. $\mathrm{DD}_{50}$ was that predicted by the respective nonlinear regression functions. 
Foerster, 2011). This study is the first to describe the fluctuations in numbers of larvae of $C$. partellus in terms of degreee-days based on in situ records collected in Turkey. Studies like this are crucial since insect pest and natural enemies often show varying levels of physiological and behavioural plasticity to changes in temperature (Mutamiswa et al., 2017).

Chilo partellus shows two distinct peaks and 1-2 insignificant peaks. There was a distinct peak in each maize growing season. The second peak occurred in the period (mixed crop) when both first and second maize crops were present in the field. In both years, there was a small (insignificant) peak very shortly after the second peak. According to Damos \& Savopoulou-Soultani (2010), such binomal peaks are of the same generation. In 2017, the first peak was a minor peak while the second was a major peak. This minor-major peak distinction was not easy to make in 2018 owing to the very slight differences between the larval counts in the first and second peaks. The first maize crop in Turkey is planted in March, however, the first record of C. partellus is in May, at a time corresponding to an accumulated degree-days of 21 from 1 May.

It is important to note that the numbers of $C$. partellus start declining and continue to do so from 6-12 August (13 weeks $\sim 344$ cumulated DD), at which time, the populations of the two major indigenous maize stem borers, $O_{s-}$ trinia nubilalis and Sesamia nonagrioides start to increase (unpubl. data). It is reported that these two indigenous maize stem borers are a major problem for the second crop of maize in Turkey (Okyar \& Kornoşor, 1997). The results revealed that although it is widely reported that temperature plays an important role in the phenology of ectotherms (e.g. insects), the relationship is not necessarily a simple linear one as is the case with C. partellus. In addition, polynomial functions (quadratic, cubic, fourth-sixth power) of the relationship between temperature and $C$. partellus phenology were also evaluated but none was able to predict its phenology to an acceptable degree. Nevertheless, AkotsenMensah et al. (2011) report that a sixth-order polynomial gives a good prediction of the flight activity of plum curculio, Conotrachelus nenuphar (Herbst) (Coleoptera: Curculionidae) in peach orchards in Alabama, United States of America.

Nonlinear regression and degree-days (DD) models are widely used to predict and monitor biological events (emergence, spatio-temporal distribution, flight activity, egg laying, egg hatch, larval abundance) of lepidopterous insects (Damos \& Savopoulou-Soultani, 2010; Pehlevan \& Kovanc1, 2017) and provide information relevant for IPM decision-making. Determination of the first and subsequent peak populations of any pest is very important for pest management. Thus, reliable models for predicting insect phenology are crucial. The parameter $\mathrm{c}$ and the $R^{2}$ values of the 'Boltzman' and logistic regressions were very similar. This indicates that both models can accurately predict the phenology of $C$. partellus on maize. Even though the values of the parameter $\mathrm{c}$ and $R^{2}$ for the 'Boltzman' and logistic regressions were very similar, the statistical evalu- ation revealed that the 'Boltzman' regression model was the better model, because of its lower corrected Akaike Information Criterion (AICc), Akaike delta scores ( $\triangle \mathrm{AICc}$ ) and Akaike weight ( $W$ i $)$ values.

These models were tested in terms of their ability to predict the $\mathrm{DD}_{50}$ when $50 \%$ of the larvae of $C$. partellus are present. The values predicted by each model are very similar. The predictive ability of both models is very high as the adjusted coefficient of determination (Adj. $R^{2}$ ) is greater than 0.80 in most cases (Damos \& Savopoulou-Soultani, 2010). The models did not accurately predict (Adj. $R^{2}<$ $0.80)$ the $\mathrm{DD}_{50}$ of the second peak in 2017. These variations are not surprising since estimates of population size often show inherent biases. Nevertheless, irrespective of the errors and other challenges that resulted in these deviations in the model's predictive abilities for the second peak in 2017 , the peak populations predicted by the models are still within acceptable limits.

\section{CONCLUSION}

In conclusion, the results of this study indicate that for larvae of Chilo partellus in the Mediterranean area of Turkey there are two major peaks, one in the first growing season (March-June) and a second at the beginning of the second growing season (June-September). The 'Boltzman' and the logistic regressions accurately predict the population dynamics of $C$. partellus. The development of models for predicting population peaks of insects is an essential component of IPM, especially those based on local in situ records. According to the models used and a starting point of 1 May, the first record of C. partellus is at $\sim 12-21 \mathrm{DD}$. The predicted $\mathrm{DD}_{50}$ for the first peak is $\sim 54-80 \mathrm{DD}$ and 45-90DD for the 'Boltzman' and logistic regressions, respectively, and that of the second peak is $~ 289-413 \mathrm{DD}$ and $\sim 252-362 \mathrm{DD}$, respectively.

It is expected that the models developed in this study will be used in IPM programs for controlling $C$. partellus in maize fields in Turkey. In addition, field evaluations in other maize growing regions in the Mediterranean should be investigated in order to develop an accurate regional forecasting system. Furthermore, we intend to improve these models based on long-term evaluations and activities of other developmental stages.

\section{DECLARATION OF CONFLICT OF INTEREST. None.}

ACKNOWLEDGEMENT. This study is funded by the Unit of Scientific Research and Projects, Çukurova Unıversity, Adana, Turkey (Project No: FDK-2018-10661), for which we are extremely grateful.

\section{REFERENCES}

Achiri D.T., Akotsen-Mensah C., Jallow M., Gbewonyo W.S.K. \& Afreh-NuAmah K. 2016: High levels of some insecticides on cabbage samples (Brassica oleracea L. var capitata) from rural and urban farms in Ghana. - J. Environ. Sci. Toxicol. Food Technol. 10: 97-103.

AKaIKE H. 1974: A new look at the statistical model identification. IEEE Trans. - Automat. Contr. 19: 716-723. 
Akotsen-Mensah C., Boozer R.T., Appel A.G. \& Fadamiro H.Y. 2011: Seasonal occurrence and development of degree-day models for predicting activity of Conotrachelus nenuphar (Coleoptera: Curculionidae) in Alabama peaches. - Ann. Entomol. Soc. Am. 104: 192-201.

ArBjafali K.H. \& JALALI S.K. 2007: Identification and analysis of host plant resistance in leading maize genetypes against spotted stem borer, Chilo partellus (Swinhoe) (Lepidoptera: Pyralidae). - Pak. J. Biol. Sci. 10: 1885-1895.

Burnham K.P. \& Anderson D.R. 2002: Model Selection and Multimodel Inference: A practical-Theoretic Approach. 2nd ed. Springer, New York, 488 pp.

Chapman J., Reynolds D.R., Smith A.D., Riley J.R., Pedgley D.E. \& WoIwoD I.P. 2002: High-altitude migration of the diamondback moth Plutella xylostella to the U.K: A study using radar, aeriel netting and ground trapping. - Ecol. Entomol. 27: 641-640.

Crespo-Perez V., Rebaudo F., Silvain J.F. \& Dangles O. 2011: Modelling invasive species spread in complex landscape: The case of potato moth in Ecuador. - Landsc. Ecol. 26: 14471461.

Damos P.T. \& Savopoulou-Soultani M. 2010: Development and statistical evaluation of models in forecasting moth phenology of major Lepidoptera peach pest complex for integrated pest management programs. - Crop Prot. 29: 1190-1199.

Del Tio R., Martinez J.L., Ocete R. \& Ocet M.E. 2001: Study of the relationship between sex pheromone trap catches of Lobesia botrana (Den. \& Schiff.) (Lep., Tortricidae) and the accumulation of degree-days in Sherry vineyards (SW of Spain). - J. Appl. Entomol. 125: 1-14.

Demir P. \& Kovanci O.B. 2015: Evaluation of the efficacy of alternative methods for control of codling moth [(Cydia pomonella L.) (Lep.: Tortricidae)] in walnut orchards. - Bitki Koruma Bül. 55: 277-304 [in Turkish, English abstr.].

Dhillon M. \& Hasan F. 2018: Consequences of diapauses on post-diapause development, reproductive physiology and population growth of Chilo partellus (Swinhoe). - Physiol. Entomol. 43: 196-206.

Intergovernmental Panel on Climate Change (IPCC) 2014: Climate change 2014: Synthesis report. In Core Writing Team, Pachauri R.K. \& Meyer L.A. (eds): Contribution of Working groups I, II and III to the Fifth Assessment Report of the Intergovernmental Panel on Climate Change. IPPC, Geneva, 151 pp.

KARUPPAIAH V. \& SUJAYANAD G.K. 2012: Impact of climate change on population dynamics of insect pests. - World J. Agric. Sci. 8: $240-246$.

Kfir R., Overholt W.A., Khan Z.R. \& Polaszek A. 2002: Biology and management of economically important lepidopteran cereal stem borers in Africa. - Annu. Rev. Entomol. 47: $701-731$

Kocourek F. \& Stara J. 2005: Predictive value of a model of the flight activity of Adoxophyes orana (Lep.: Tortrichidae). $-J$. Pest Sci. 78: 205-211.

Kumar H. 2002: Resistance in maize to larger grain borer, Prostephanus truncatus (Horn) (Coleoptera: Bostrichidae). $-J$. Stor. Prod. Res. 38: 267-280.

Lactin D.J., Holliday N.J., Johnson D.L. \& Craigen R. 1995: Improved rate model of temperature-dependent development by arthropods. - Environ. Entomol. 21: 68-75.

Machekano H., Mutamiswa R., Mvumi B.M., Nyabako T., Shaw S. \& NyamuKondiwa C. 2019: Disentangling factors limiting diamondback moth, Plutella xylostella (L.) spatio-temporal population abundance: A tool for pest forecasting. - J. Appl. Entomol. 143: 670-682.
Manyangarirwa W., Zehnder G.W., McCutcheon G.S., Smith J.P., Alder P.H. \& Mphuru A.N. 2009: Parasitoids of the diamondback moth on brassicas in Zimbabwe. - Afr. Crop Sci. Confer. Proc. 9: 565-570.

Marchioro C.A. \& Foerster L.A. 2011: Biotic factors are more important than abiotic factors in regulating the abundance of Plutella xylostella L. (Lepidoptera: Plutellidae) as a function of temperature: Effect on the number of generations in tropical and sub-tropical regions. - Neotrop. Entomol. 40: 533-541.

Mosiane S.M., Kfir R. \& VilLet M.H. 2003: Seasonal phenology of the diamondback moth, Plutella xylostella L. (Lepidoptera: Plutellidae) and its parasitoid on canola Brassica napus (L.) in Gauteng Province, South Africa. - Afr. Entomol. 11: 277-285.

Mudavanhu P., Addison P. \& Ken L.P. 2011: Monitoring and action threshold determination for the obscure mealybug Pseudococcus viburni (Signoret) (Hemiptera: Pseudococcidae) using pheromone-baited traps. - Crop Prot. 30: 919-924.

Mutamiswa R., Chidawanyika F. \& Nyamukondiwa C. 2017: Comparative assessment of the thermal tolerance of spotted stemborer, Chilo partellus (Lepidoptera: Crambidae) and its larval parasitoid, Cotesia sesamiae (Hymenoptera: Braconidae). - Insect Sci. 25: 847-860.

Ofomata V.C., Overholt W.A., Lux S.A., Van Huis A. \& EgwUATU R.I. 2000: Comparative studies on the fecundity, egg survival, larval feeding and development of Chilo partellus and Chilo orichalcociliellus (Lepidoptera: Crambidae) on five grasses. - Ann. Entomol. Soc. Am. 93: 492-499.

OKYAR Z. \& KoRnoşor S. 1997: Determination of Noctuidae (Lepidoptera) species in Trakya region II. - Turk. J. Entomol. 21: 197-212 [in Turkish].

Overholt W.A., Songa J., Ofomata V. \& Jeske J. 2000: The spread and ecological consequences of the invasion of Chilo partellus (Swinhoe) (Lepidoptera: Crambidae) in Africa. In Lyons E. \& Miller S. (eds): Invasive Species in Eastern Africa: Proceedings of a Workshop Held at ICIPE, 5-6 July, 1999, Nairobi, Kenya, 2000. ICIPE Science Press, Nairobi, pp. 52-58.

Pehlevan B. \& Kovanci O.B. 2017: Using degree-day and nonlinear regression models to predict seasonal flights of Adoxophyes orana (Fischer von Roslerstamm, 1834) (Lepidoptera: Tortricidae) in plum orchards. - Turk. J. Entomol. 41: 75-86.

PotTER D.A. 1981: Seasonal emergence and flight of northern and southern masked chafers in relation to air and soil temperature and rainfall patterns. - Environ. Entomol. 10: 793-797.

Pruess K.P. 1983: Day-degree methods for pest management. Environ. Entomol. 12: 613-619.

Rahman M.T. \& KhalequZZAman M. 2004: Temperature requirements for the development and survival of rice stemborers in laboratory conditions. - Entomol. Sin. 11: 47-60.

Rauf A., Ayyaz M., Baig F., Naqqash M.N. \& Arif M.J. 2017: Response of Chilo partellus (Swinhoe) and entomophagous arthropods to some granular and new chemistry formulations in Zea mays L. - J. Entomol. Zool. Stud. 5: 1351-1356.

SertKaya E., Akmese V. \& Atay E. 2014: First record of spotted stem borer Chilo partellus (Swinhoe) (Lepidoptera: Crambidae) on maize Turkey. — Turk. Entomol. Bull. 4: 197-200.

VAN DEN BERG J. 2006: Oviposition preference and larval survival of Chilo partellus (Lepidoptera: Pyralidae) on Napier grass (Pennisetum purpureum) trap crops. - Int. J. Pest Manag. 52: $39-44$.

Yonow T., Darren K.J., Ota N., Van den Berg J. \& William D.H. 2017: The potential global distribution of Chilo partellus, including consideration of irrigation and cropping patterns. J. Pest Sci. 90: 459-477.

Received June 22, 2019; revised and accepted January 24, 2020 Published online February 7, 2020 